\title{
QU
}

\section{REFLEXÕES SOBRE O ATENDIMENTO PRESTADO AOS ALUNOS COM NECESSIDADES EDUCACIONAIS ESPECIAIS (NEE) NA CIDADE DE APODI/RN}

LIMA, B. G. (IFRN)* ; OLIVEIRA NETO, F. B. (IFRN); FERNANDES, A. N. O. (IFRN)

\section{RESUMO}

Tem crescido a cada ano a preocupação de ofertar ensino de qualidade, para todas as pessoas e também para as que possuem alguma NEE, a partir disso foram elaboradas uma série de medidas que visam proporcionar um atendimento de qualidade para esses indivíduos, nunca deixando de lado o princípio da inclusão. O presente trabalho tem como objetivo fazer um diagnóstico por meio de questionários a respeito do serviço oferecido aos alunos com NEE. Nos questionários se abordou o número de professores que possuíam formação específica para atender esses alunos, como também a procura pela sala de Atendimento Educaional Especializado (AEE), frente ao número de alunos com necessidades especiais. Respaldamos-nos em documentos legais que versam sobre a inclusão. Como resultados, percebemos que ainda há uma carência de profissionais qualificados para receber esse público.

PALAVRAS-CHAVE: Inclusão, NEE, formação continuada.

\section{REFLECTIONS ON THE SERVICE PROVIDED TO STUDENTS WITH SPECIAL EDUCATIONAL NEEDS (SEN) IN APODI/RN}

\begin{abstract}
Has grown each year the concern to offer quality education to all the people and also to those with some $\mathrm{NEE}$, from that were prepared a series of measures to provide quality care for these individuals, never leaving aside the principle of inclusion. The present work aims to make a diagnosis by means of questionnaires regarding service offered to students with special needs,
\end{abstract}

in the questionnaires if addressed the number of teachers with specific training to meet these students, but also demand for the ESA, in front of the number of students with special needs. Support us in legal documents relating to inclusion. As a result, we realize that there is still a shortage of qualified professionals to receive this public.

KEY-WORDS: Inclusion, SEN, continuing education. 


\section{REFLEXÕES SOBRE O ATENDIMENTO PRESTADO AOS ALUNOS COM NECESSIDADES EDUCACIONAIS ESPECIAIS (NEE) NA CIDADE DE APODI/RN}

\section{INTRODUÇÃO}

A escola deve ser capaz de garantir a igualdade de oportunidades numa sociedade cada vez mais desigual. Perante este desafio importa, entre outras dimensões, identificar os meios utilizados pela instituição escolar para combater práticas onde ainda predomina a indiferença, face às diferenças individuais e é neste contexto que a intervenção do professor pela natureza das suas funções, adquire particular significado. Ao procurar introduzir valores, conhecimentos e práticas que contrariam ideologias dominantes e pressupostos de tradicionais métodos de ensino, o professor constitui-se como um impulsionador de processos de mudança, podendo contribuir para o desenvolvimento de comunidades educativas solidárias e tolerantes para a criação de uma cultura escolar onde a democracia, a igualdade e a dignidade humana constituam os valores de referência (MADUREIRA, 2014).

Nas últimas décadas, diversas ações foram realizadas a fim de garantir o acesso ao ensino regular para pessoas com NEE, tais como: a Lei de Diretrizes e Bases da Educação Nacional (Lei no 9.394, de 20 de dezembro de 1996) que conceituou a Educação Especial como modalidade de educação escolar, oferecida preferencialmente na rede regular de ensino, para educandos portadores de necessidades especiais (Lei no 9.394, 1996, Capítulo V, Art. 58); o Programa de Educação Inclusiva: Direito à Diversidade em 2006, que visava melhorar a formação de gestores e educadores; e em 2007 o Plano de Desenvolvimento da Educação - PDE que também objetivou a formação de educadores e o acesso de todos à escolarização.

Com tais políticas, passou a ocorrer uma gradual substituição da oferta de ensino para as escolares públicas regulares em detrimento das instituições de educação especial, que até então monopolizavam o ensino de tal população. A matrícula das pessoas com deficiência passou então a ocorrer em salas comuns das escolas públicas, e com isso houve o surgimento do (AEE). Tal processo é observado no Decreto 6.571/2008, cuja Resolução n.o 4, de 2009, instituiu as Diretrizes Operacionais para o Atendimento Educacional Especializado (GUERRA et all, 2015).

A educação das pessoas com deficiência efetiva-se mediante a garantia de chances para sua plena participação em igualdade de condições com as demais pessoas, na comunidade em que vivem, promovendo oportunidades de desenvolvimento pessoal, social e profissional, sem restringir sua participação em determinados ambientes e atividades, com base na deficiência (SANTOS, 2015). 
Tendo em vista o que foi exposto o presente trabalho tem como objetivo caracterizar o atendimento oferecido para os alunos com NEE pela Escola Estadual Professor Gerson Lopes e Escola Estadual Professor Antônio Dantas, além do Centro de Atendimento Especializado Geovania Andrade de Morais na cidade de Apodi/RN.

\section{MATERIAIS E MÉTODOS}

Após o levantamento bibliográfico acerca do assunto em estudo, foram aplicados questionários em duas escolas do município de Apodi/RN, uma que atende a alunos do ensino fundamental II (A) e outra que atende alunos do ensino médio (B), também foi aplicado um questionário no Centro de Atendimento de Educação Especial Geovania Andrade de Morais, na cidade de Apodi RN.

Tais questionários servem como meio de identificar pontos positivos e negativos presentes no serviço oferecido pelas escolas, além disso os questionários permitem conhecer melhor cada instituição e como cada uma delas trata a problemática da inclusão dos alunos com NEE.

\section{RESULTADOS E DISCUSSÕES}

Após a análise dos dados obtidos com os questionários foi possível obter os seguintes resultados:

Ao analisar a formação dos professores que atuam diretamente em sala de aula foi possível perceber uma carência no serviço ofertado aos alunos com necessidades especiais como demonstrado nos gráficos 1 e 2 a seguir:

Gráfico 1. Formação dos professores que atuam na escola.

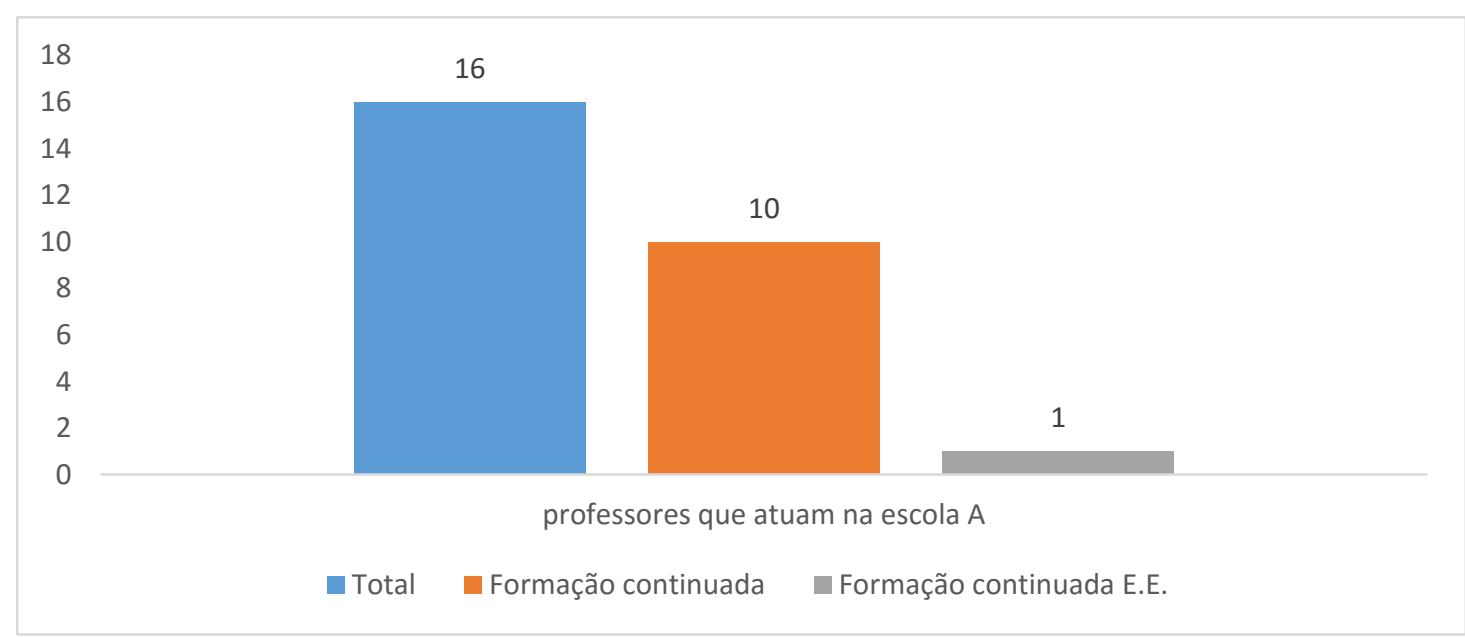

Fonte: Elaborado pelos autores. 
Gráfico 2. Formação dos Professores da escola B

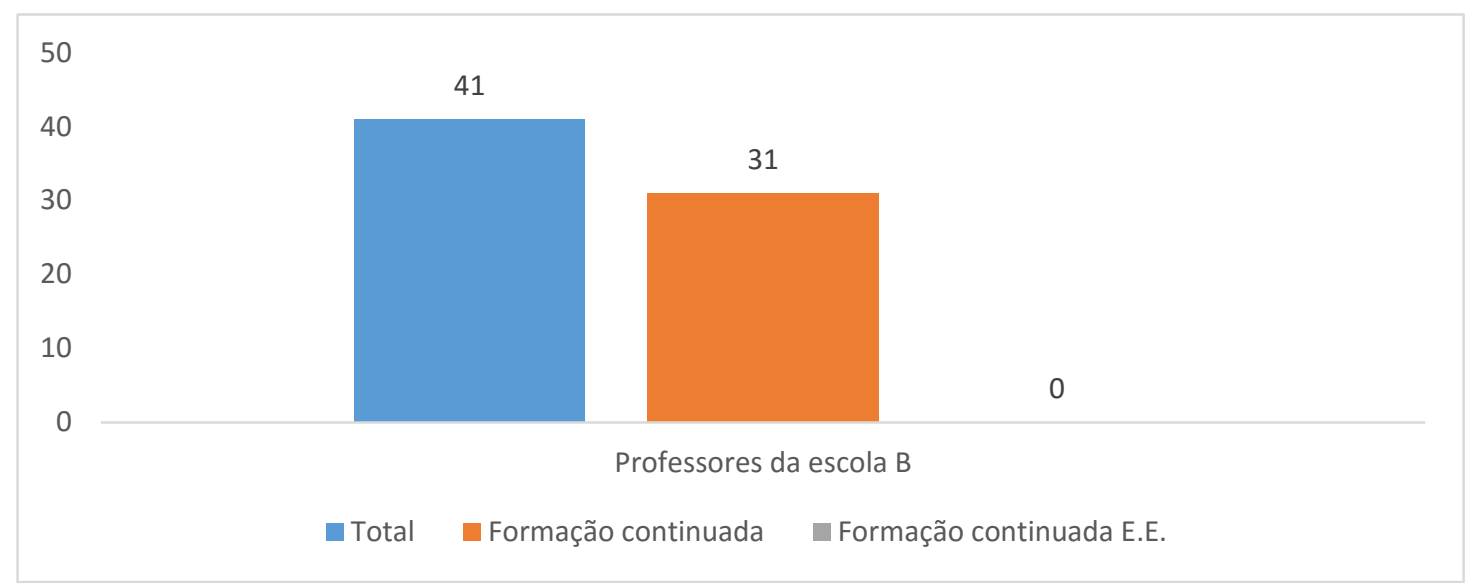

Fonte: Elaborado pelos autores.

Com os dados obtidos foi possível perceber que há uma deficiência em ambas as instituições de professores com formação apropriada para receber alunos que possuem alguma NEE, essa carência pode ser explicada pelo fato de que a inclusão de alunos com necessidades especiais nas salas regulares é um fato relativamente novo, desta forma ainda é pequena a porcentagem de professores que buscam uma melhor capacitação para atender esse público em específico.

Em contrapartida a essa condição as escolas dispõem de salas de $A E E$, onde os alunos recebem uma formação complementar em sala de aula, os gráficos a seguir demonstram o perfil do atendimento ofertado nessas salas.

Gráfico 3. Perfil dos alunos da escola A

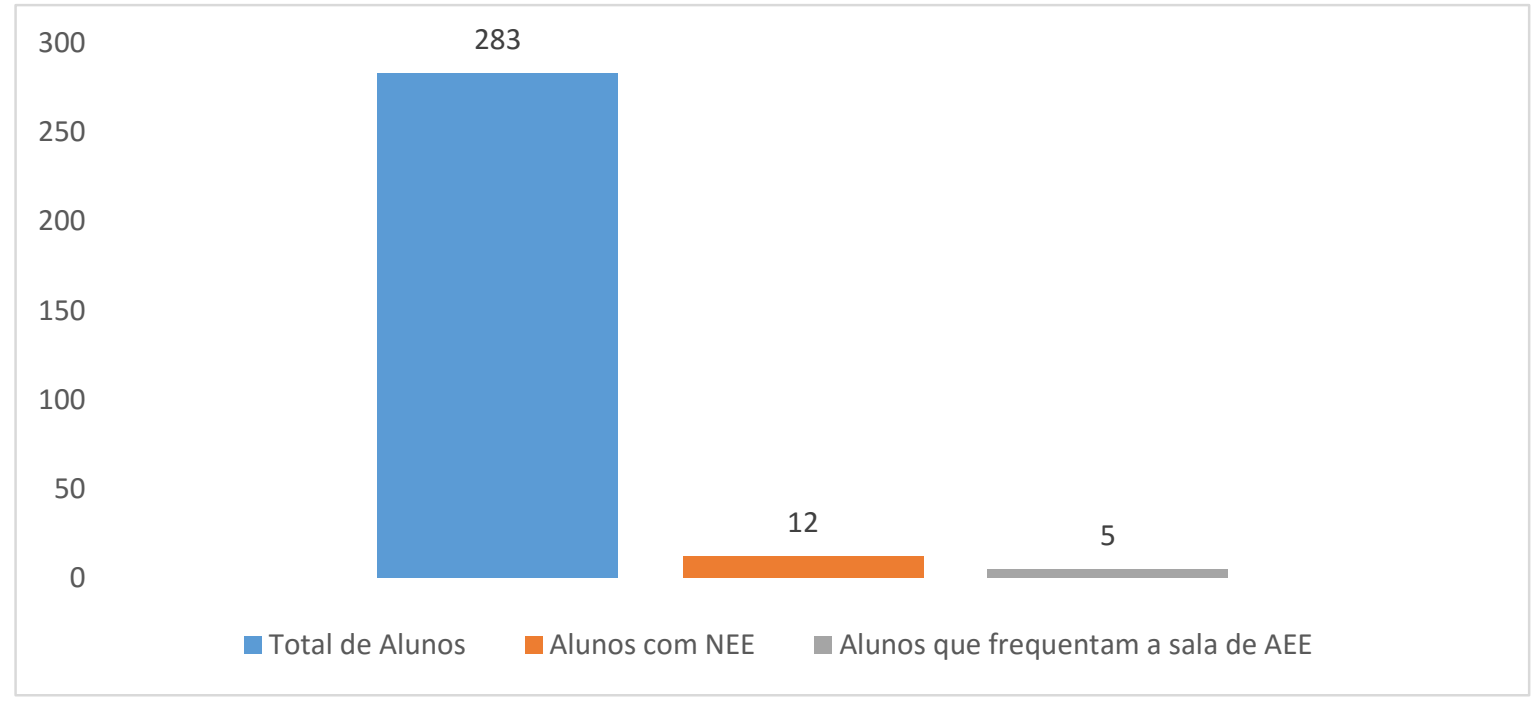

Fonte: elaborado pelos autores.

4a Semana de Química - IFRN, 2016 
Gráfico 4. Perfil dos alunos da escola B

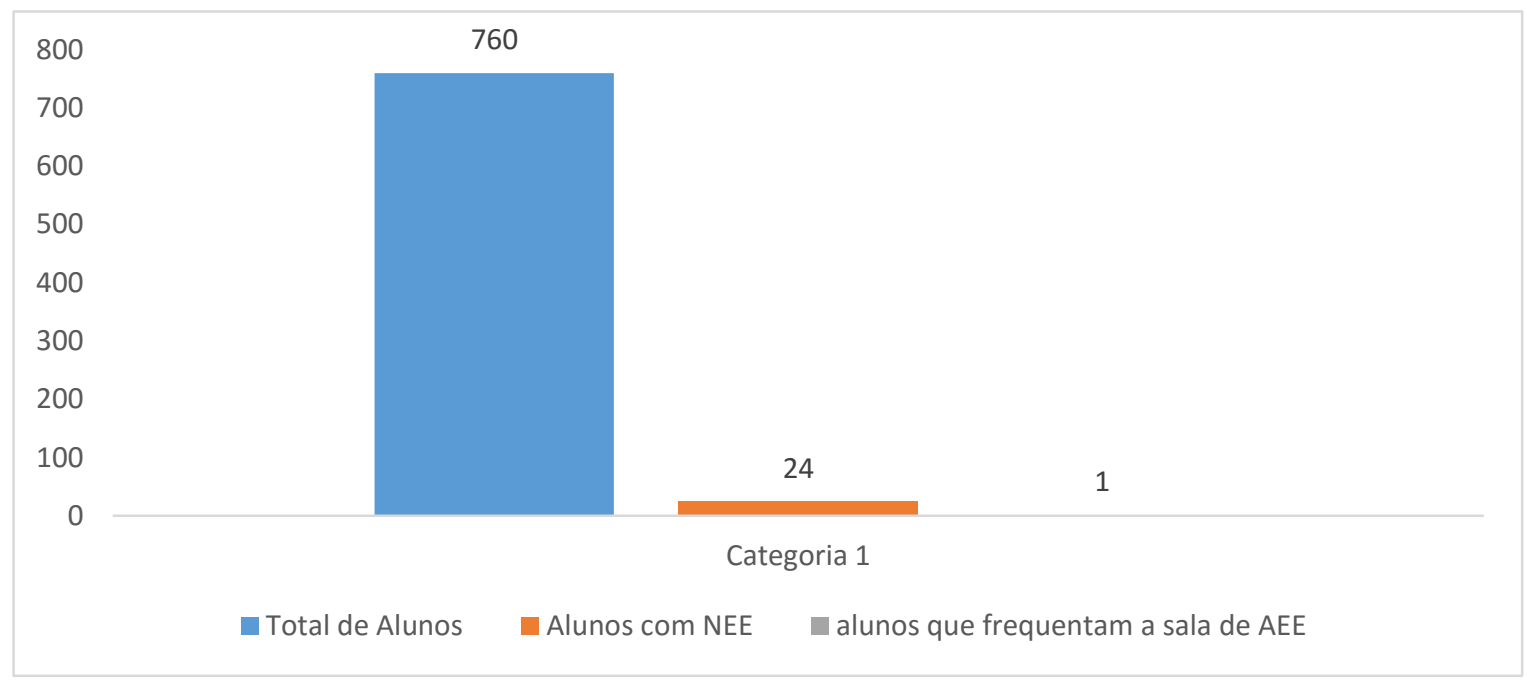

Fonte: Elaborado pelos autores.

Como observado nos gráficos 3 e 4, há uma demanda razoável de alunos que precisam de atendimento nas salas de A.E.E., entretanto há uma diferença significativa entre o número de alunos que deveriam receber esse atendimento e o número de alunos que efetivamente são atendidos por elas.

Em ambas as escolas é possível refletir sobre o porquê dessa discrepância, na escola $A$, que oferta ensino a nível fundamental II essa diferença pode ser explicada devido a uma parte significativa desses alunos serem da zona rural, e isso é um fator dificultador para se deslocarem até o centro de atendimento. Já na escola B é ofertado apenas o ensino médio, desta forma alguns alunos podem se sentir inibidos a frequentarem essa sala, devido ao bullying que sofrem dos colegas, outro fator apontado pelo diretor do $A E E$, é o preconceito que os próprios pais tem com seus filhos, pois eles não aceitam seus filhos com deficiência, quando a família visita o centro se deparam com a diversidade e resistem em deixar seus filhos.

No momento da entrevista o Centro de Atendimento Especializado Geovania Andrade de Morais atendia 78 pessoas que possuem variadas necessidades especiais, segundo a própria instituição esse número varia pois, ao longo do ano há desistências, ou novas matrículas. $O$ centro busca realizar além de atividades voltadas ao ensino, palestras e caminhadas pela inclusão, com a finalidade de diminuir o preconceito existente na população.

\section{CONCLUSÃO}

O trabalho demonstra que ainda há uma deficiência no atendimento prestado a alunos que possuem NEE, uma vez que persiste uma carência no mercado de professores que possuam as competências necessárias para atender de forma eficiente esse público, além de uma visão, ainda preconceituosa que a população tem a respeito desse assunto. 
É preciso então realizar um trabalho efetivo, tanto na comunidade escolar quanto junto a população em geral, demonstrando a importância de se realizar sempre uma formação continuada no caso dos professores e também de convidar a comunidade externa a conhecer um pouco da realidade das pessoas com necessidades especiais, bem como o trabalho desenvolvido pelas instituições de ensino para que essas pessoas tenham as mesmas oportunidades que qualquer outro cidadão.

\section{AGRADECIMENTOS}

Os autores agradecem ao Instituto Federal de Educação, Ciência e Tecnologia do Rio Grande do Norte - IFRN, Campus Apodi, as escolas que participaram deste estudo e ao Centro de Atendimento de Educação Especial Geovania Andrade de Morais.

\section{REFERÊNCIAS}

GUERRA, B.T., ROVARIS, J. A., MARIANO, M., GUIDUGLI, P. M., ROSANTI, S., BOLSONISILVA, A. T. B., Análise das queixas da rede municipal encaminhadas para a Educação Especial. Revista Quadrimestral da Associação Brasileira de Psicologia Escolar e Educacional, São Paulo. V 19, N 2, p321-328, 2015.

MADUREIRA, I. P., Professores de educação especial - socialização e identidades Profissionais. Investigar em educação, n 2, 2014.

SANTOS, M. C. D., O direito das pessoas com deficiência à Educação Inclusiva e o uso pedagógico dos recursos de Tecnologia Assistiva na promoção da acessibilidade na escola. Revista InFor, n 1, 2015 